\title{
The 14th European Colorectal Congress (\#ECCStGallen), 29 November-2 December 2020, St. Gallen, Switzerland
}

\author{
M. Adamina ${ }^{1,2} \cdot$ J. Lange ${ }^{3} \cdot$ G. Pozza ${ }^{1} \cdot$ F. Ris $^{4} \cdot$ V. Delaune ${ }^{4}$ on behalf of the E. C. C. Scientific Committee
}

Published online: 10 October 2021

○) Springer Nature Switzerland AG 2021

\section{Introduction}

With the second wave of the COVID-19 pandemic in full swing in Europe, organizers of the 14th European Colorectal Congress (ECC) had to think on their feet and hastily rearrange this year's congress, held from November 29th to December 2nd 2020, in its first ever virtual format. Participants were invited to $\log$ on to the ECC website and follow lectures online. There were surprisingly few technical difficulties throughout the meeting, with interesting lectures given by 45 experts on a variety of topics such as COVID-19 and surgical patient management, management of rectal cancer, gut microbiota and its impact on colorectal oncogenesis, and many more. Industry satellite symposiums were maintained in this virtual congress. The full program of the ECC 2020 congress comprised 50 state-of-the-art lectures and it was accredited for $21 \mathrm{CME} / \mathrm{CPD}$ credits (Fig. 1).

The virtual congress kicked off on Sunday November 29th with two simultaneous sessions: the classic Masterclass in Colorectal Surgery, and its first ever Course in Proctology. Both courses were vastly successful with 1403 participants staying connected throughout the day.

The Masterclass was introduced by Michel Adamina (Fig. 2). Frédéric Ris had the difficult task to start the course with the very controversial topic of bowel prep and antibiotic usage in decreasing surgical site infection in colorectal surgery, referencing the recent ORALEV [1] and MOBILE [2]

M. Adamina

michel.adamina@gmail.com

1 Department of Surgery, Colorectal Surgery, Kantonsspital Winterthur, 8401 Winterthur, Switzerland

2 Department of Biomedical Engineering, CRAIS, University of Basel, Allschwil, Switzerland

3 Medkongress AG, Rorschacherstrasse 311, 9016 St. Gallen, Switzerland

4 Department of Visceral Surgery, Geneva University Hospitals, Geneva, Switzerland studies, and stressing the need for further prospective studies on their impact on the microbiome. Paris Tekkis went on to discuss the management of the rare colorectal GIST, and Roel Hompes showed us his ever-impressive videos illustrating the diagnosis and minimally invasive removal of large rectal adenomas and malignant polyps. Phil Quirke reminded us why pathologists are the surgeons' and the oncologists' closest allies in the treatment of colorectal cancer, explained the cutting edge technology that can be used to tailor patient adjuvant treatment in colorectal cancer, also touching on the widely popular gut microbiome, its impact on colorectal oncogenesis, anastomotic leak and response to check-point inhibitor therapy. The importance of patient prehabilitation in colorectal cancer, the use of radiotherapy for organ preservation in rectal cancer, and new techniques for avoiding double-staple lines in colorectal surgery were addressed by Des Winter, Chris Cunningham and Antonio Spinelli. Willem Bemelman took on the difficult task in countering recent controversies surrounding TaTME in rectal cancer, by speaking of the excellent results of the Dutch experience; he recalled the specific dos and don'ts, and insisted on the fact we have been too quick to widely implement and then shoot down this technique, when it is a difficult surgery, with a slow learning curve. Finally, long-term follow-up of the GRECCAR 5 trial outcomes were outlined by Quentin Denost, reporting an overall rate of $23 \%$ of pelvic sepsis after rectal surgery for cancer, advising on management of said sepsis, and finding that patients with clinically relevant sepsis have significantly worse disease-free $(<50 \%)$, overall $(76 \%)$ and distant recurrence-free $(52 \%)$ survival at 3 years. Eva Angenete finished the course by tackling the best practices in colostomy construction and repair of parastomal hernia.

Bruno Roche introduced the new Course in Proctology which was focused on common functional diseases of the perineum and anus. Alexander Herold reported new procedures for treating complex anorectal fistula and shared his strategies on how personalizing treatment. Technical 


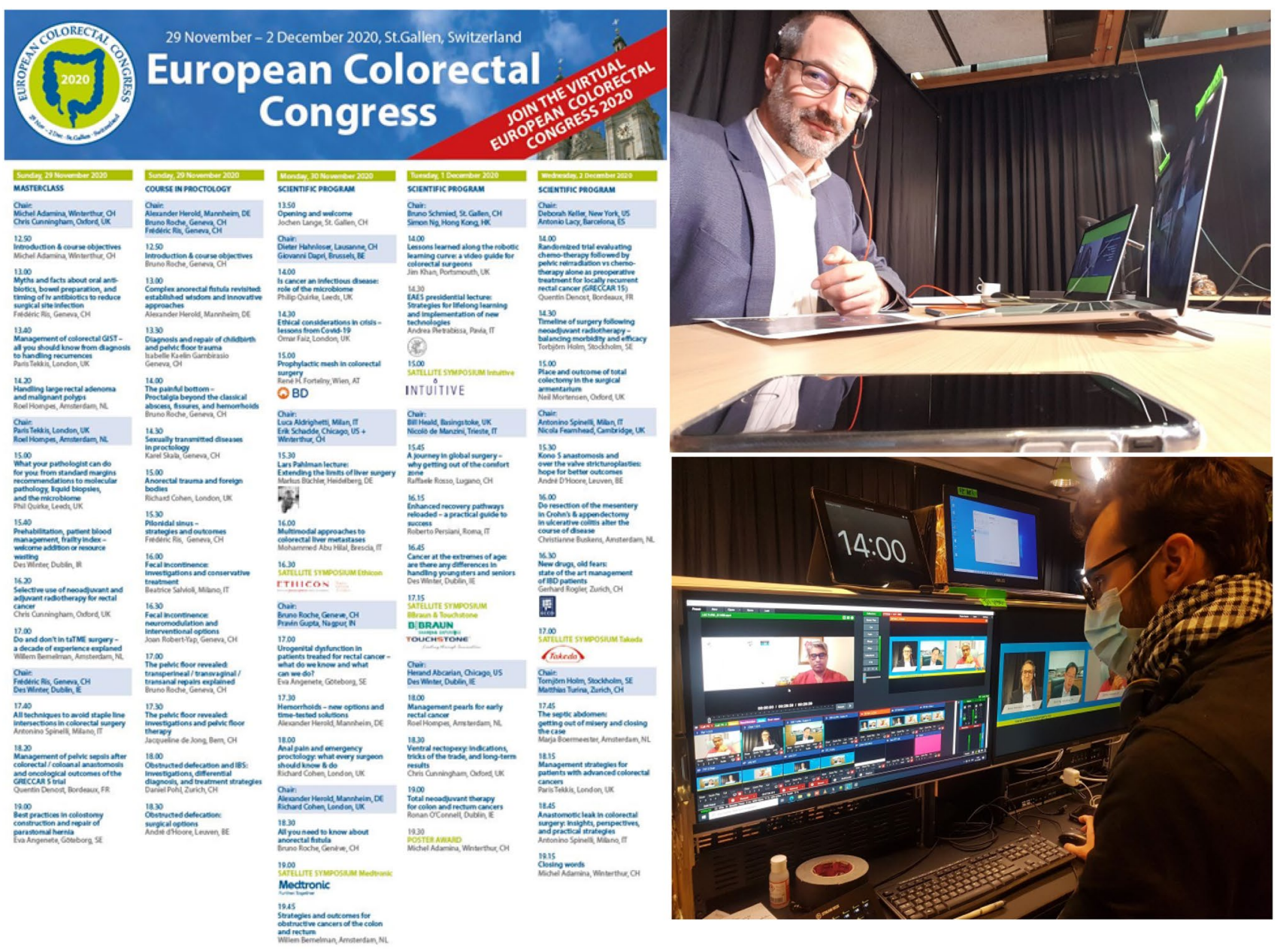

Fig. 1 The programme of the 14th European Colorectal Congress of St. Gallen, including its Masterclass in Colorectal Surgery and its Course in Proctology, and a view from the back office during the live congress

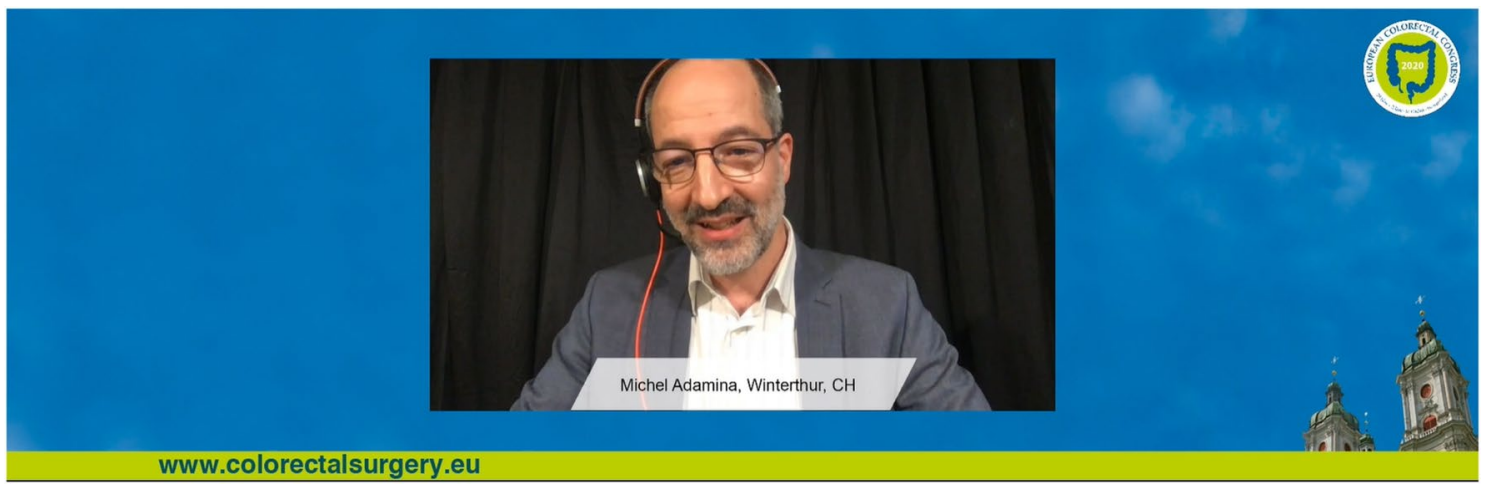

Fig. 2 Michel Adamina introducing the Masterclass in Colorectal Surgery at the first ever virtual version of the European Colorectal Congress

points and outcomes of surgery for pilonidalis sinus disease were discussed by Frederic Ris. Karel Skala gave an overview of sexually transmitted infections in proctology and gave practical advice on detecting HPV-related lesions in the anal canal. Assessment and treatment of pelvic floor trauma were thoroughly discussed from a gynecological point of view by Isabelle Kaelin Gambirasio and from a proctological perspective by Richard Cohen. Leading expert 
in perineology Bruno Roche held two lectures: the first one focused on differential diagnosis and treatment of chronic pelvic pain with particular attention to essential anorectal pain; in the second one, he shared his knowledge of different surgical approaches when dealing with pelvic floor repairs. Beatrice Salvioli and Joan Robert fully discussed fecal incontinence and the best stepwise approach, while Jacqueline de Jong spoke about the role of physiotherapy in functional anorectal disorders. Daniel Pohl talked about inflammatory bowel syndrome and its conservative management, and finally, decision-making regarding the surgical approach to obstructed defecation syndrome was discussed by André D'Hoore.

Jochen Lange welcomed the online users to the main congress that started on Monday November 30th (Fig. 3), promising us that this would be the first and last virtual congress. Philip Quirke gave the first lecture on the role of the gut microbiome in colorectal oncogenesis (Fig. 4), identifying particular bacteria (Fusobacterium nucleatum, and also toxin-producing bacteria) as potential oncomicrobes, and highlighting the need for further research as our knowledge is still widely lacking. Omar Faiz went on to talk about the most Googled topic of 2020: COVID-19. He echoed our collective feelings of strangeness during the first wave, with eerily quiet hospitals and empty cities, and pinpointed the ethically difficult decision-making process during the first wave, personal benefits coming secondary to societal interests, with increased damage-control surgeries and less curative cancer surgeries in favor of the treatment of COVID-positive patients. The first session was concluded by a lecture from René H. Fortelny, on behalf of BD Bard, on the use of prophylactic mesh in colorectal surgery, reminding us of the guidelines on the prevention of incisional hernia; he argued for the use of prophylactic onlay mesh in at-risk patients on midline incisions, prophylactic 3D mesh in definitive stoma, and retromuscular mesh after stoma closure.

Markus Büchler gave an excellent Lars Påhlman lecture on extending the limits of resection of colorectal cancer liver metastases (Fig. 5), drawing on a recent review of the literature [3] and exploring the current approaches to increase resectability. Mohammed Abu Hilal closed this

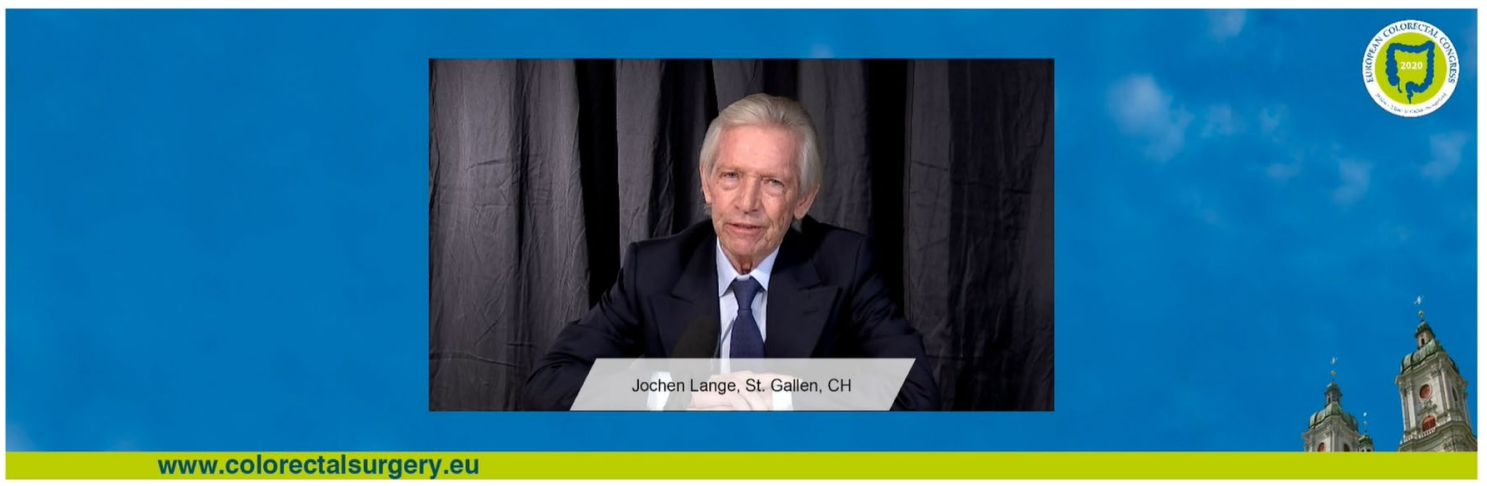

Fig. 3 Jochen Lange welcomes congress participants to this first and last, he promises, virtual session of the European Colorectal Congress

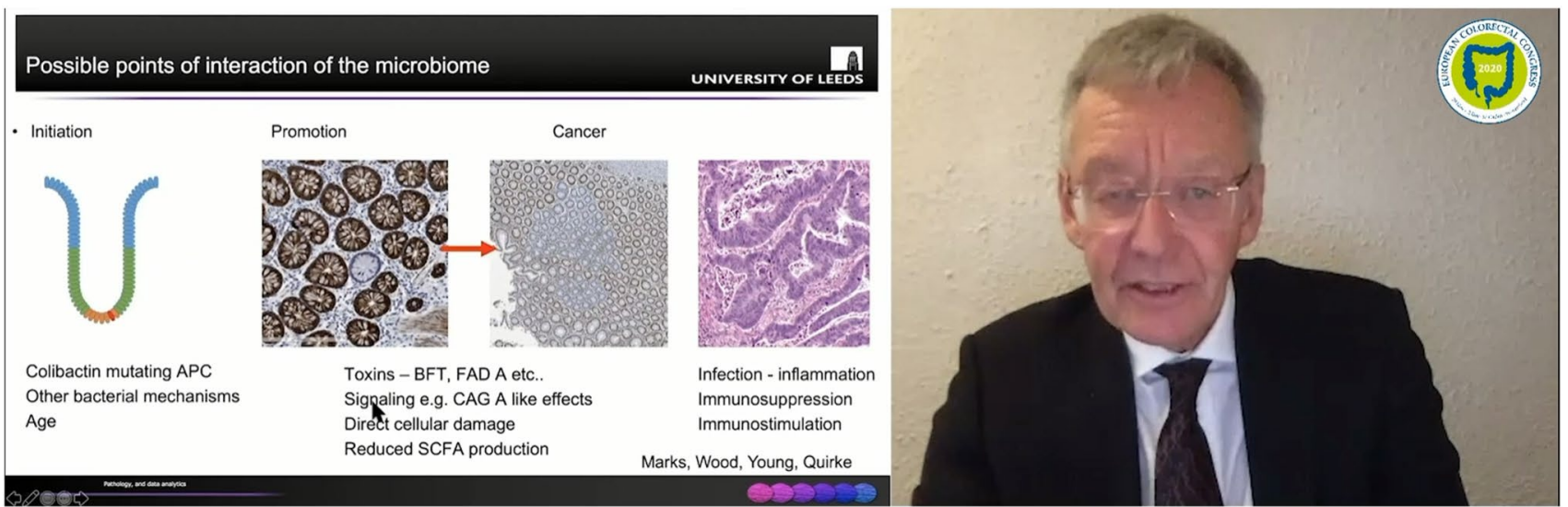

Fig. 4 Philip Quirke explaining the increasing evidence linking gut microbiome and colorectal cancer, highlighting a possible pathophysiological pathway 


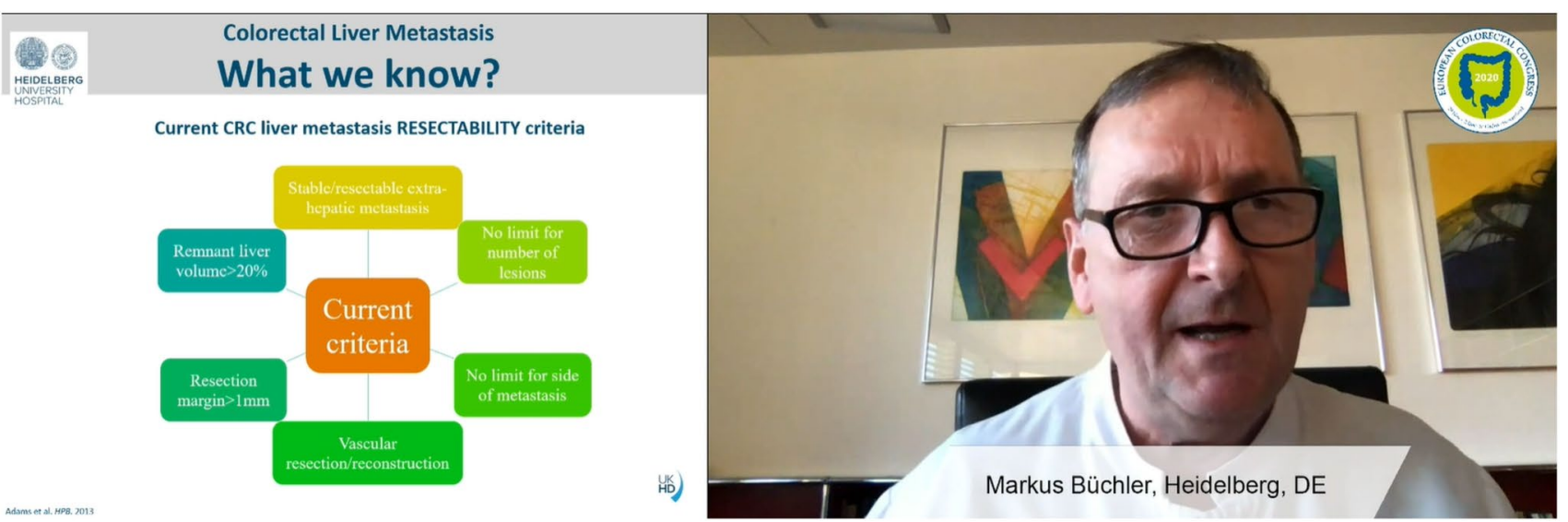

Fig. 5 Markus Büchler pushing the boundaries of colorectal cancer liver metastasis surgery during the Lars Påhlman lecture

liver surgery parenthesis by pushing the limits of laparoscopic surgery in the resection of multiple liver metastases from colorectal cancer.

The late afternoon session of the first day was focused on the pelvic floor and proctology, with Eva Angenete brilliantly opening the discussion on the complicated topic of managing urogenital dysfunction after rectal cancer treatment, insisting on patient-tailored treatment by a specialist. This was followed by three lectures walking us through the treatment of hemorrhoids, the management of anal pain and emergency proctology and the anorectal fistula, given by Alexander Herold, Richard Cohen and Bruno Roche. Willem Bemelman concluded the first day of the congress by exposing strategies and outcomes for obstructive cancers of the left colon and rectum, comparing bridge to definitive surgery by stenting versus decompressive stoma, trying to decrease morbidity and targeting an oncologically curative surgery, concluding that the use of a stent is an excellent option as a bridge to surgery, providing the center has gastroenterologists skilled in the procedure.

Day two of the congress started off with fascinating lectures on the use "new technologies" in colorectal surgery. Jim Khan, as an adept robotic surgeon, discussed effective and safe standardized teaching methods of robotic rectal surgery for fellows, and showed us the full scope of robotics in advanced colorectal cancer surgery. Andrea Pietrabissa gave an inspiring EAES presidential lecture, notably addressing the problematic stagnation of hands-on surgical training due to COVID-19-restricted operations. He suggested the use of 3D-printed organs not only in pre-operative surgery planning, but also as the potential future in resident surgical training, having continued this program (with model kidney transplantation) during the pandemic while elective surgery is at a standstill (Fig. 6). The afternoon continued with a beautiful talk given by Raffaele Rosso on his enrollment in Doctors Without Borders and the major lack of safe surgical structures in the vast majority of the globe. Roberto Persiana talked to us about the updated enhanced recovery

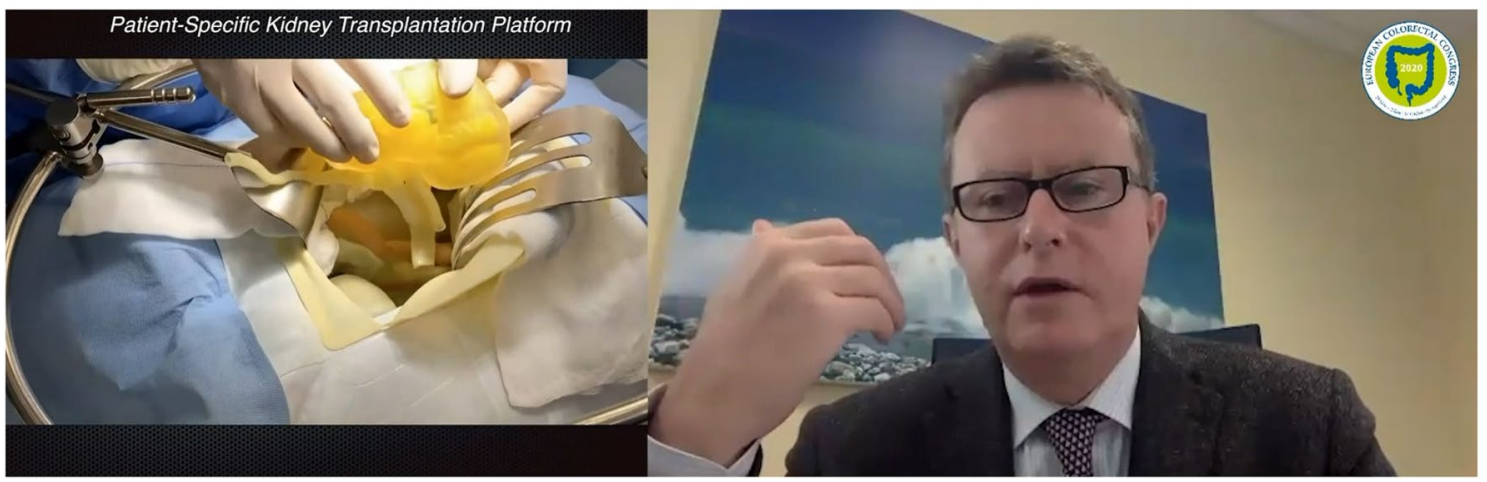

Fig. 6 Surgery residents in Pavia, Italy, performing a model kidney transplantation using Andrea Pietrabissa's 3D-printed organs, as an alternate activity during the elective surgery standstill due to the COVID-19 pandemic 
pathways with the introduction of the notion of prehabilitation [4], as discussed by Des Winter in the Masterclass course, and revealing that enhanced recovery protocols are still not widely implemented despite unquestionable results. Des Winter then discussed the challenge of managing the ever-younger (20-40 age group) colorectal cancer patients that we see in our practice. He tried to explain the reasons for this trend of increasingly young patients presenting cancer, notably the impact of well-known lifestyle and environmental factors, but also the gut microbiota, Triclosan and genetics. These young patients seem to have a higher rate of stage III disease, due to delayed diagnosis, with better overall survival but worse disease-free survival. Of note, as these patients tend to survive longer than older patients special care must be taken in deciding the best oncotherapeutic strategy; organ-preservation options look appealing but we have to take into consideration the risk of long-term difficulties in function and sexual activity, and the increased risk in developing chemoradiotherapy-induced secondary cancer. Roel Hompes went on to stress the importance of accurate endoscopic polyp assessment, using narrow-band imaging, in the early detection of $\mathrm{T} 1$ rectal cancers and in choosing adequate endoscopic or TAMIS resection. A very exhaustive lecture on laparoscopic ventral rectopexy, with tips and tricks and suggestions on complication management, was given by Chris Cunningham. Last, but certainly not least, Ronan O'Connell gave the final lecture of the day, tackling a very controversial topic, total neoadjuvant therapy for colon cancer and rectal cancer. He drew on a very interesting study dating from 2015 [5], showing that by delaying rectal surgery at 26 weeks and adding a complete post-radiotherapy adjuvant therapy of mFOLFOX6 (i.e. total neoadjuvant therapy), complete pathological response was obtained in 38\%; these results seem to be reproducible according to a systematic review published last year [6], although further studies are still needed. The rationale of total neoadjuvant therapy is logical, in that it allows for the completion of oncological therapy with improved compliance due to reduced toxicity. The early results of the RAPIDO trial conclude that total neoadjuvant therapy lowers the rate of disease-related treatment failure, and of distant metastases, and that the high rate of complete pathological response can contribute to organ preservation. Concerning advanced colon cancer, the soonto-be published FOxTROT study and the PROBE study [7] show that there is a high rate of tumor response and a trend towards increased disease-free and survival rates when patients undergo neoadjuvant chemotherapy for colon cancer or obstructive colon cancer. Ongoing studies may give us further conclusive evidence.

The second day of the main congress concluded with the best poster award 2020 of 10,000 EUR, having to choose between a staggering number of submitted posters (178). The award was given to Dr. Pankaj Kumar (Fig. 7), Dr.

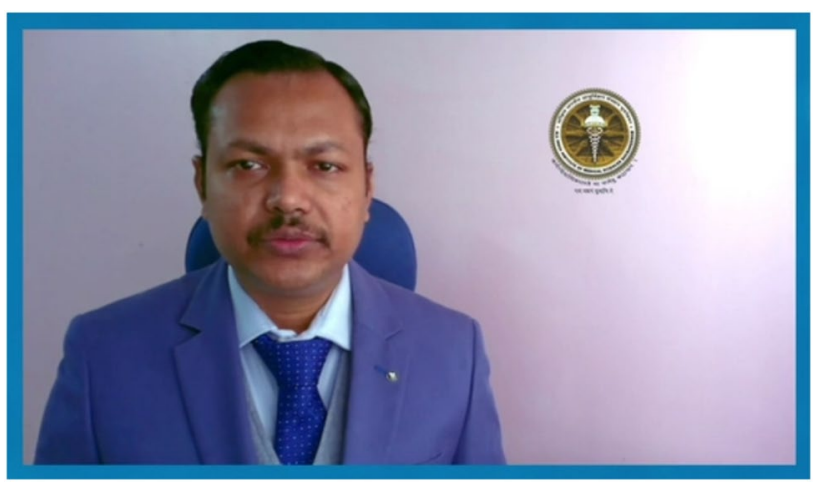

Fig. 7 Best poster award 2020 recipient, Dr. Pankaj Kumar, from Bhubaneswar, India

Siddanth Sarthak, Dr. Tushar Mishra, and Dr. Prakash Kumar Sasmal from Bhubaneswar, India, for their randomized control trial FRAIL "LIFT vs ERAF in patients with high fistula in ano (FRAIL trial): Interim analysis". Briefly, their interim analysis suggests improved healing, shorter operative time, less immediate post-operative pain, and better quality of life at 6 months in the LIFT group. All accepted abstracts were published in Techniques in Coloproctology [8].

The third and final day of the main congress got off to a flying start with Quentin Denost presenting the basis of the GRECCAR 15 trial. It is a randomized trial evaluating pre-operative therapy regimes in recurrent rectal cancer, performed on recurring patients without metastasis at inclusion time, and having received radiotherapy in the treatment of the initial cancer; its primary endpoint is R0 resection. Balancing the morbidity and efficacy of neoadjuvant radiotherapy and adequately timing surgery for rectal was then discussed by Torbjörn Holm.

The afternoon continued on the topic of inflammatory bowel disease. Neil Mortensen talked of the place of total colectomy in inflammatory bowel disease, notably in acute severe ulcerative colitis. Those patients who have not responded to rescue therapy within 7 days should undergo subtotal colectomy and ileostomy. Surgery guidelines include special care while dissecting the splenic flexure, where perforation is most likely to occur, be mindful of cancer risk when considering vessel division, leave a long rectal stump and a rectal drain to avoid a blowout, try to make the best ileostomy possible, and try minimally invasive surgery if feasible to decrease adhesion formation. The next talk by André D'Hoore focused on the best surgical management to try and decrease recurrence of fibrotic strictures in Crohn's disease. He advocates for the Kono-S anastomosis to decrease the risk of inlet strictures found after sideto-side anastomoses, the excision of mesentery to reduce recurrence, and unconventional stricturoplasty to save small 


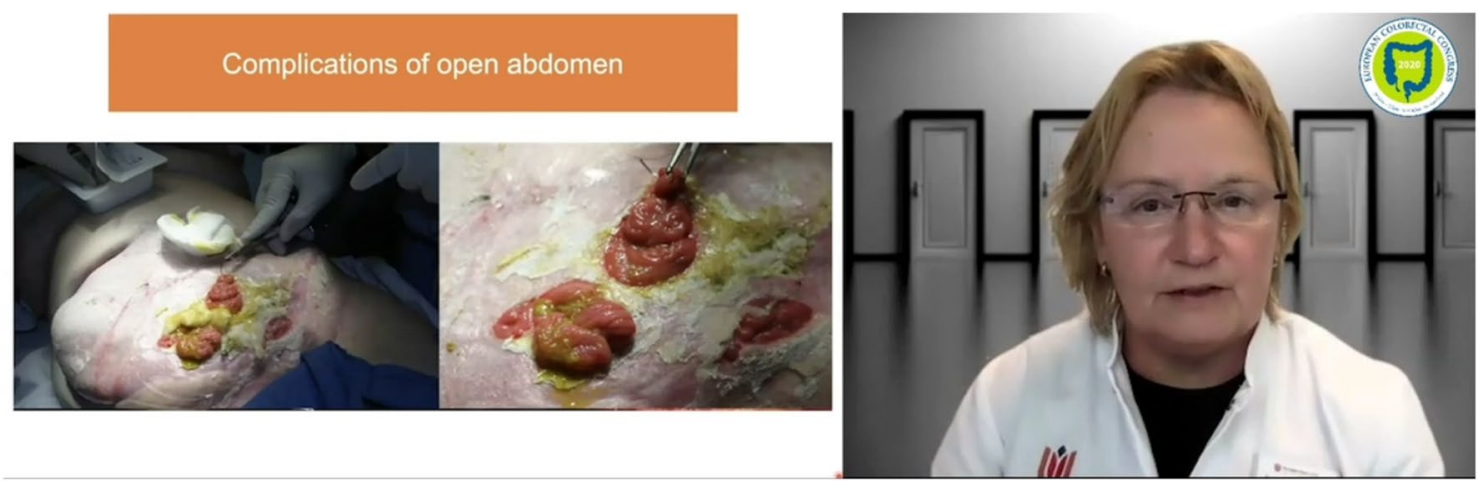

Fig. 8 Marja Boermeester giving tips on the prevention of abdominal catastrophes after laparotomy for septic abdomen

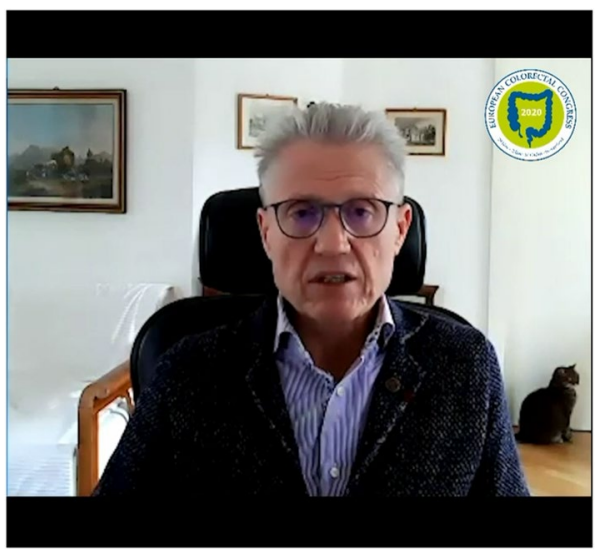

Fig. 9 René H. Fortelny's cat making a noted appearance in the lecture on prophylactic mesh in colorectal surgery

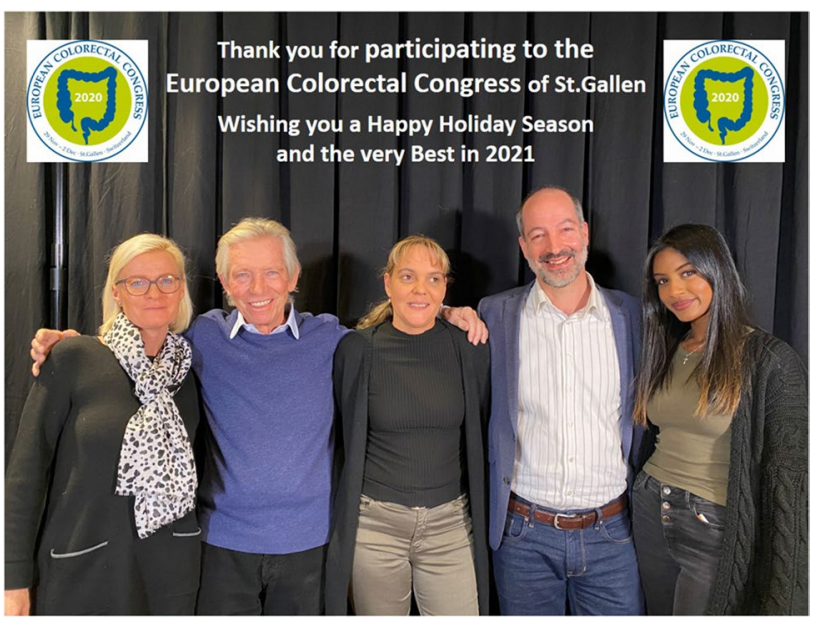

Fig. 10 Michel Adamina, Evelyne Thür, Corinne Weerakon, Jochen Lange, and Rebecca Anthony, for closing words of this virtual congress intestine length in cases of long terminal ileum strictures. Christianne Buskens rebounded on the topic of mesentery resection in Crohn's and appendectomy in ulcerative colitis. The jury still seems to be out on the role of the mesentery in Crohn's disease; it does harbor pro-inflammatory cytokine-producing macrophages, the creeping fat seems to be a protective response against systemic dissemination of gut bacteria [9]. It is clear that appendectomy in childhood reduces the risk of developing ulcerative colitis, and there is promising data on its role in preventing relapse and postponing colectomy, but further confirmation is still needed. Gerhard Rogler, gastroenterologist, closed the IBD session by giving a comprehensive update on currently available drugs, notably developing specific risks of new therapies with respect to opportunistic infections.

The final lectures of this year's congress focused on surgical catastrophes. The first of them was given by Marja Boermeester, stressing the importance of closure of the abdomen after surgery for peritonitis, in the absence of extreme hemodynamic instability, to avoid long-term abdominal wall complications (Fig. 8). Paris Tekkis thoroughly demonstrated the absolute necessity of multidisciplinary management, and referral to specialized centers, of patients with advanced colorectal cancer. For the final lecture of the main congress, Antonino Spinelli took to the floor once more to address the ever-problematic anastomotic leaks in colorectal surgery. A big concern is the absence of consensus on the definition of an anastomotic leak, leading to uncertain incidence rates with huge differences in reports. However, it is a certainty that an anastomotic leak is troublesome, with increased morbidity and mortality, but also local cancer recurrence [10]. The microbiome is the hot topic of the moment, and its impact on the occurrence of anastomotic leaks seems certain; however, more studies are needed to shed light on its role. He shared tips to avoid the modifiable factors that put anastomoses at risk of leaking. 
Fig. 11 The programme of the 15th European Colorectal Congress of St. Gallen includes again live surgery by Expert Surgeons, Consultants' corners, and in addition to the established Masterclass in Colorectal Surgery and Course in Proctology it will feature another course in Hernia Surgery

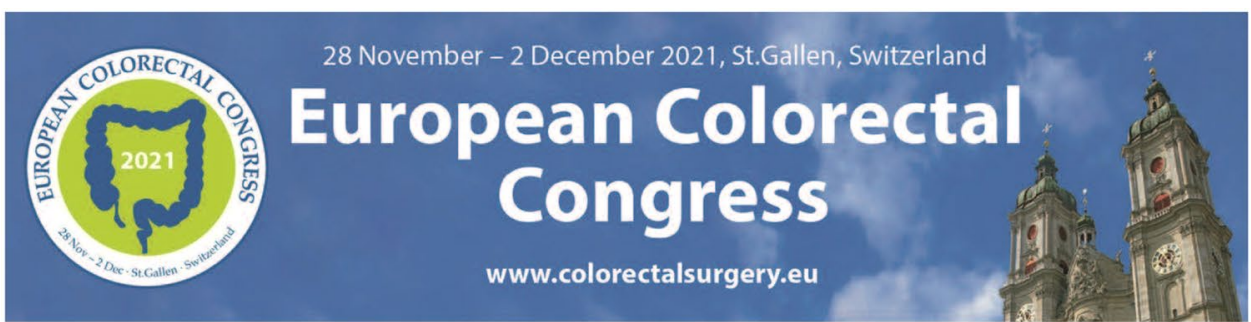

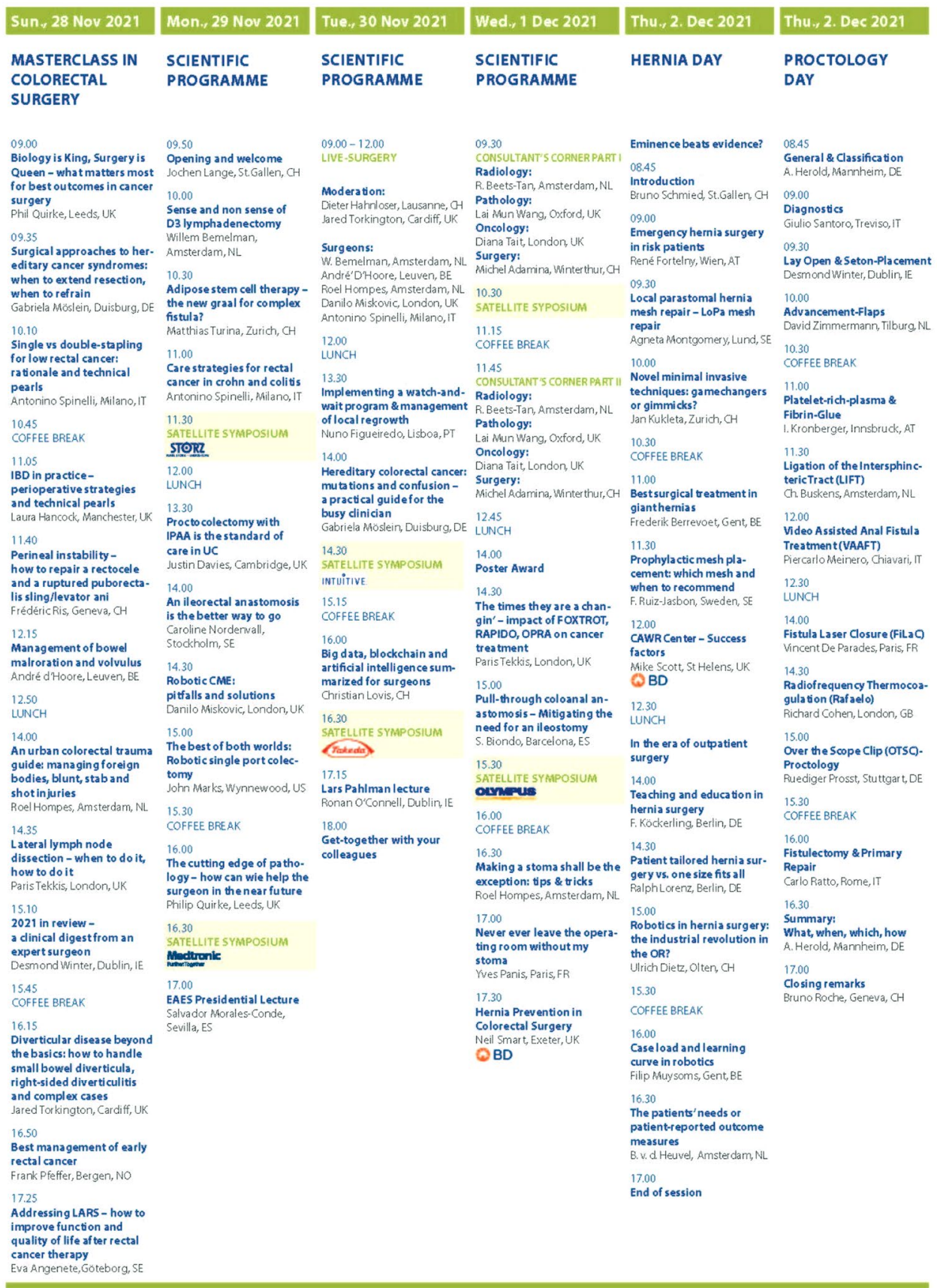




\section{Conclusion}

Overall, this virtual congress was a resounding success, with record-breaking 1,403 participants from 81 countries, excluding the odd cat hidden behind René Fortelny (Fig. 9). The key improvements were the possibility to access lectures at any time, allowing some of us to carry on in our daily work routines and watching the videos at our convenience, and mostly the new poster presentation format, allowing for a much livelier and stimulating interaction.

We would like to wholeheartedly thank Evelyne Thür, Corinne Weerakoon, Rebecca Anthony (Fig. 10), for their hard work, and the Faculty and Participants for making this first ever virtual ECC congress a success.

Although there is something to be said on the comfort of hiding behind a chat room to ask questions, speakers and chairmen greatly regretted having to talk to blank screens. We, therefore, all hope for the return of real, living and breathing, interactions at next year's 15th European Colorectal Congress in St. Gallen, Switzerland, which will be held from November 28th to December 1st, 2021. The programme of the upcoming congress is set (Fig. 11) - stay tuned for the return of live surgeries with expert surgeons Willem Bemelman, André D'Hoore, Roel Hompes, Danilo Miskovic, and Antonino Spinelli. As well, we will revive the much appreciated Consultants' corner with its lively discussion of challenging cases, even for seasoned experts. Last but not least, a 1-day course on hernia surgery will be introduced, in addition to the popular Masterclass in Colorectal Surgery and Course in Proctology.

\section{Declarations}

Conflict of interest The authors declare that they have no conflict of interest or financial ties to disclose related to this work.

Ethical approval This article does not contain any studies with human participants performed by the authors.

Informed consent Informed consent is not applicable for this Congress Report.

\section{References}

1. Espin Basany E, Solís-Peña A, Pellino G, Kreisler E, Fraccalvieri D, Muinelo-Lorenzo M et al (2020) Preoperative oral antibiotics and surgical-site infections in colon surgery (ORALEV): a multicentre, single-blind, pragmatic, randomised controlled trial. Lancet Gastroenterol Hepatol 5(8):729-738

2. Koskenvuo L, Lehtonen T, Koskensalo S, Rasilainen S, Klintrup K, Ehrlich A et al (2019) Mechanical and oral antibiotic bowel preparation versus no bowel preparation for elective colectomy (MOBILE): a multicentre, randomised, parallel, single-blinded trial. The Lancet 394(10201):840-848

3. Schadde E, Grunhagen DJ, Verhoef C, Krzywon L, Metrakos P (2020) Limitations in resectability of colorectal liver metastases 2020 - a systematic approach for clinicians and patients. Semin Cancer Biol. https://doi.org/10.1016/j.semcancer.2020.09.008

4. Gustafsson UO, Scott MJ, Hubner M, Nygren J, Demartines N, Francis N et al (2019) Guidelines for perioperative care in elective colorectal surgery: enhanced recovery after surgery (ERAS®) society recommendations: 2018. World J Surg 43(3):659-695

5. Garcia-Aguilar J, Chow OS, Smith DD, Marcet JE, Cataldo PA, Varma MG et al (2015) Effect of adding mFOLFOX6 after neoadjuvant chemoradiation in locally advanced rectal cancer: a multicentre, phase 2 trial. Lancet Oncol 16(8):957-966

6. Zaborowski A, Stakelum A, Winter DC (2019) Systematic review of outcomes after total neoadjuvant therapy for locally advanced rectal cancer. Br J Surg 106(8):979-987

7. Ishibe A, Watanabe J, Suwa Y, Nakagawa K, Suwa H, Misumi T et al (2020) A prospective, single-arm, multicenter trial of diverting stoma followed by neoadjuvant chemotherapy using $\mathrm{mFOL}-$ FOX6 for obstructive colon cancer: YCOG 1305 (PROBE study). Ann Surg. https://doi.org/10.1097/SLA.0000000000004494 (Online ahead of print)

8. Adamina M, Pozza G, \#ECCStGallen Scientific Committee (2021) Abstracts presented at the 14th European Colorectal Congress (\#ECCStGallen), 29.11.2020-2.12.2020, St. Gallen, Switzerland. Tech Coloproctol 607-656. https://doi.org/10.1007/s10151-02102408-9. Online ahead of print

9. Ha CWY, Martin A, Sepich-Poore GD, Shi B, Wang Y, Gouin $\mathrm{K}$ et al (2020) Translocation of viable gut microbiota to mesenteric adipose drives formation of creeping fat in humans. Cell 183(3):666-683.e17

10. Ma L, Pang X, Ji G, Sun H, Fan Q, Ma C (2020) The impact of anastomotic leakage on oncology after curative anterior resection for rectal cancer: a systematic review and meta-analysis. Med (Baltim) 99(37):e22139

Publisher's Note Springer Nature remains neutral with regard to jurisdictional claims in published maps and institutional affiliations. 